Esta revista forma parte del acervo de la Biblioteca Jurídica Virtual del Instituto de Investigaciones Jurídicas de la UNAM

\title{
El Instituto Nacional de Elecciones Entrevista a José Woldenberg
}

¿Qué opinas sobre las propuestas de crear un INE?

Los firmantes del Pacto por México anuncian una reestructuración mayor y radical de los órganos encargados de la organización electoral, los senadores del PRD y el PAN sólo contemplan la posibilidad de que el Instituto Federal Electoral (IFE) se haga cargo de elecciones locales en circunstancias extremas. El Congreso, por supuesto, deberá decidir.

Ahora bien, de que ambas cosas se pueden hacer no tengo duda alguna. Tareas más ambiciosas se han emprendido y alcanzado en el ámbito electoral. De tal suerte que el terreno de la discusión no es ese, sino si se deben dar esos cambios, porque de poder, se pueden.

¿Consideras que los argumentos de que sería más barato el INE o de que los institutos locales han perdido autonomía frente a los gobernadores son correctos?

El primer argumento, debo decirlo, no me parece suficiente. Anteponerlo a la dimensión política de la operación, a las derivaciones que tendría, es un error. La típica miopía de quien ve lo menos y no lo más. Pero asimismo no es claro que la medida, por lo menos en el corto plazo, ofrezca ese resultado. Me explico. 
La organización actual del IFE, lo sabemos, sigue la estructura electoral federal, es decir, sus unidades, las juntas ejecutivas distritales (y en el proceso electoral, sus consejos), están instaladas en todos y cada uno de los distritos en los que se divide la geografía electoral - son $300-$, y en ellas se desarrolla lo fundamental del trabajo comicial. Pues bien, esa estructura no coincide en la mayoría de los casos con la estructura electoral local, y los desfases son considerables. Solo algunos ejemplos por estricto orden alfabético, Aguascalientes tiene tres distritos federales y dieciocho locales, Baja California ocho y dieciséis respectivamente; Baja California Sur dos y dieciséis; Campeche dos y veintiuno; Chiapas doce y veinticuatro; Chihuahua nueve y veintidós; Coahuila siete y dieciséis; Colima dos y dieciséis, etcétera.

Pero ¿qué nos dicen esos números? Que en algunos estados el IFE convertido en INE "sólo" tendría que multiplicar su estructura distrital por dos (Chiapas), pero en otros casos por más de diez (Campeche).

Señalo lo anterior solo para subrayar que la presunción de que abarataría considerablemente el gasto electoral no resulta clara.

El segundo argumento es - desde mi punto de vista- el relevante, se afirma que los institutos electorales estatales han sido desnaturalizados, que han dejado de ser imparciales (o que siempre fueron parciales), que han perdido su autonomía (o que nunca la tuvieron) y han sido succionados por sus respectivos gobernadores. Creo que es una generalización excesiva, las realidades en los distintos estados son disímiles, y quizá valga la pena recordar que tenemos gobernadores de diferentes partidos y congresos con muy diversas composiciones.

Digo esto porque hasta donde entiendo seguimos siendo una República federal y teóricamente los estados que componen la República deben tener las posibilidades de dotarse de las instituciones encargadas de los procesos de los que deben emerger sus gobernantes y legisladores.

Me pregunto si es correcto que dados algunos problemas políticos pretendamos una y otra vez centralizar procesos sustantivos que deberían, en lo fundamental ser operados por y desde los Estados.

Por supuesto, el Constituyente Permanente puede modificar esa disposición, pero ¿qué tipo de federalismo estaremos construyendo si cada vez que nos topamos con una complicación tendemos a centralizar las instituciones encargadas de solucionarlo?

Me hago cargo, sin embargo, que ese primer argumento les puede resultar débil a muchos. Y no solo eso, les puede sonar como una pantalla para encubrir todo tipo de excesos por parte de los gobernadores, 
una cortina de humo para fomentar las tropelías. Dirán algunos, una bonita teoría que acaba justificando todo tipo de abusos.

Valdría quizás entonces revisar lo que esa estructura electoral ha contribuido a generar en el mundo de la representación. Hay quien dijo que por sus resultados los conoceréis (aunque en este caso sería un exceso, porque los resultados de las elecciones dependen de la voluntad de los electores y no de quienes organizan los comicios). Pero "algo" nos dirá acercarnos al mundo de los datos de la representación, veamos, hemos vivido a partir de 1989 fenómenos de alternancia en las gubernaturas en por lo menos los siguientes estados, Baja California, Guanajuato, Chihuahua, Jalisco, Querétaro, Nuevo León, Zacatecas, Aguascalientes, Tlaxcala, Baja California Sur, Nayarit, Chiapas, Michoacán, Yucatán, Guerrero, Oaxaca, Puebla, Sinaloa, San Luis Potosí, Sonora, Morelos, Tabasco, Distrito Federal — veintitrés entidades-, y en algunos casos, de ida y de vuelta. Hoy, solo o con aliados el Partido Revolucionario Institucional (PRI) gobierna veintiún estados, pero otros once son gobernados por el PAN, el PRD y diferentes coaliciones.

En 1988, en treinta y un congresos locales el PRI tenía mayorías calificadas, once años después en 1999, esa situación solo se daba en uno. El año pasado se eligieron quince congresos locales (estoy incluyendo en la suma a la Asamblea del Distrito Federal), en siete de ellos ningún partido logró la mayoría absoluta de asientos, en cuatro esa mayoría es del PRI, en tres del PRD y en uno del PAN.

En 1977 solo cuatro municipios eran gobernados por partidos diferentes al PRI. Once años después la suma había crecido a treinta y nueve, y once años después, en 1999, eran quinientos ochenta y tres municipios. Hoy, PRD, PAN y otros gobiernan novecientos siete municipios.

Es decir, el pluralismo político no solo vive y se reproduce en la sociedad sino en las instituciones del Estado. Esas cifras nos hablan de elecciones competidas, de fenómenos de alternancia, de que en muchas entidades el reparto del poder es efectivo y cambiante.

\section{Con el INE, se dice, se busca homogeneizar procedimiento, ¿qué opinión te merece esto?}

México es un mosaico desigual de tradiciones, historias, comunidades, que han generado peculiaridades políticas y correlaciones de 
fuerzas singulares. Ese mural abigarrado y diverso, fruto como diría el teórico de un "desarrollo desigual y combinado", debe tener forma de expresarse y recrearse a través de mecanismos singulares. No todo se puede y debe homogeneizar, y menos por decreto. Traigo a la mesa de discusión solamente los más de cuatrocientos ayuntamientos que en Oaxaca se eligen bajo la fórmula de usos y costumbres.

Pero además está la esfera de los conflictos. Esperar que los procesos comiciales se desarrollen sin conflictos, no es más que utópico, la vida y más la vida política significa, entre otras cosas, pugnas, desencuentros, esgrimas. La promesa de erradicarlos por completo es eso, una promesa ilusoria. Por supuesto que resulta racional intentar disminuirlos, y más aún ofrecerles un cauce seguro para su resolución, y en ese terreno ¿no será mucho mejor que sean los institutos locales los que atiendan esos diferendos que mandatar a un órgano federal para arbitrarlos y desahogarlos? No solo porque los locales están más cerca de los litigios y conocen mejor el terreno, sino porque además parece conveniente no federalizar lo que eventualmente es un conflicto local acotado. Nuestro sistema hace que un agudo diferendo político en un pequeño o grande municipio sea hoy (quizá) un problema estatal. Si quien hubiese organizado esa elección fuera una autoridad federal lo que tendríamos sería un conflicto federal, nacional. Hay que pensarlo bien, para que la medicina no resulte más perjudicial que la enfermedad.

\section{Con esta idea de no federalizar los conflictos locales, ¿consideras que es necesario delimitar algunas facultades tanto del IFE como en los institutos locales?}

Se debe establecer que los institutos no serán más jueces, ya que contamos con una vía jurisdiccional para resolver los conflictos. Hace apenas unas semanas escribía en relación al IFE lo siguiente -pero donde digo IFE bien puede escucharse institutos electorales locales¿Entre más facultades concentre una autoridad mejor para ella? Depende, ¿eso la fortalece? Puede debilitarla, ¿conviene? No se puede contestar inercialmente,

el aumento sustancial en la presentación de quejas durante los procesos electorales obliga a la revisión de los procedimientos especiales sancionadores, con el fin de preservar su eficacia, sin afectar la organización electoral. En el borrador del "Libro blanco" que elabora el IFE se reconoce 
la importancia de analizar si es preciso mantener esta facultad en el organismo o trasladarla al área judicial... ${ }^{1}$

Si bien en la nota se apuntaba que el documento aún se estaba discutiendo entre consejeros y representantes de los partidos políticos y que faltaba que fuera aprobado - o no- por el Consejo General del propio Instituto, para ser entregado al Congreso, el asunto resulta capital.

El IFE, como se sabe, tiene encomendadas diferentes funciones, pero simplificando al máximo se podría decir que hoy tiene que (1) organizar todos los eslabones del proceso electoral, al tiempo que cada vez más (2) se convierte en un juez de los litigios entre partidos e incluso en el seno de los mismos. Y mientras en la primera esfera de sus competencias logra de manera recurrente el apoyo de los representantes de los partidos, en la segunda eso resulta imposible.

Desde hace un buen rato las diferencias entre los partidos y el IFE en materia de organización de las elecciones son casi inexistentes. El padrón, las listas nominales, la credencial para votar; el sorteo, capacitación y nombramiento de los funcionarios de casilla; la infraestructura electoral, los materiales, las boletas y actas; el Programa de Resultados Electorales Preliminares, los conteos rápidos; la distritación, y súmenle ustedes, son más espacios de acuerdos que de divergencias. El diálogo permanente que los consejeros mantienen con los representantes de los partidos y el profesionalismo probado de la rama ejecutiva del propio Instituto, ayudan a forjar amplias zonas de convergencia; pero hay que decirlo: la materia de trabajo lo posibilita porque —en teoría y en la práctica- hay comunidad de intereses en ese terreno.

No obstante, cuando un partido acusa a otro de lo que usted guste o mande, el IFE no puede dejar satisfechas a ambas partes. Mientras quien acusa quiere que se condene, quien es acusado reclama salir absuelto, y como en todo juicio, el juez debe darle la razón a uno o a otro, no puede ni debe tratar de quedar bien con ambos porque el código genético de un juicio lo hace imposible. El círculo se cierra porque toda resolución del Instituto puede ser recurrida ante el Tribunal Electoral (y qué bueno que así sea) para evitar que el IFE se convierta en una autoridad omnipotente y para ofrecer garantías a los partidos.

1 Alonso Urrutia, "Plantean apartar de las facultades del IFE la aplicación de sanciones", La Jornada, 2 de abril de 2013. 
Pero ese diseño genera de manera periódica fricciones entre el IFE y los partidos y entre el Instituto y el Tribunal (aunque claro, el segundo es siempre la última palabra).

El problema reside en que al convertir a una autoridad administrativa (eso es el IFE) en una especie de juez, no solo se promueven roces entre la autoridad y los "entes regulados" (como se ha puesto de moda llamarlos), sino se desvirtúa y erosiona el encargo del Instituto, y ello sucede porque - ni modo- el Consejo General del IFE no fue diseñado para ser un órgano jurisdiccional, sus consejeros no son magistrados, en el Consejo están sentados los representantes de los partidos y del Poder Legislativo, y además, todas sus resoluciones casi de manera inercial, son impugnadas ante el Tribunal, y mal harían los partidos en no hacerlo, ya que tienen todo que ganar y nada que perder.

Sería mejor, dado que el Tribunal Electoral es un órgano jurisdiccional, sus integrantes son magistrados, su encargo es precisamente el de dirimir litigios y su estructura es biinstancial, que los querellantes acudieran a las salas regionales del mismo en demanda de justicia y la Sala Central siguiera siendo la instancia definitiva y última del juicio.

Recordemos que al inicio (1993-1996), por ejemplo, en materia de fiscalización de los recursos de los partidos el IFE actuaba como una especie de ministerio público (realizaba la investigación), pero era el Tribunal el encargado de fijar o no las sanciones correspondientes. La fiscalización era y es una tarea en la cual el Instituto no puede alinearse con los partidos (como si lo puede hacer en materia de organización electoral), sino todo lo contrario, está obligado a colocarse frente a ellos y ser inquisitivo ante los mismos, pero por lo menos, en aquellos años no aparecía como un juez de primera instancia.

Quizá volver a la idea básica de que el IFE organiza las elecciones y el Tribunal desahoga y resuelve los conflictos, podría sentar mejores condiciones para la reproducción armónica y sustentable no solo de nuestros dos pilares institucionales en materia comicial, sino de las elecciones todas.

Algo similar se podría hacer con los institutos locales, máxime, hay que recordarlo, que sobre los institutos ya hay un control de legalidad por parte de los tribunales locales y de legalidad e incluso de constitucionalidad por parte del Tribunal Electoral del Poder Judicial de la Federación. 


\section{Y en materia de control judicial de las elecciones ¿nos hace falta algo?}

Luego de casi diecisiete años de funcionamiento en el que todas las controversias entre partidos, o entre ellos y la autoridad administrativa electoral han sido resueltas por el Tribunal y acatadas por los partidos - lo cual se escribe fácil pero es una de las construcciones civilizatorias más relevantes de los últimos años-, sabemos -o deberíamos saber- que los órganos electorales administrativos (tanto locales como el federal) están sujetos a la vigilancia de dicho Tribunal. Las ventajas están a la vista, se trata de un Tribunal probado, con experiencia y con amplias facultades, y los partidos litigantes están acostumbrados y obligados a respetar sus resoluciones. Recordemos, además, que los senadores de todos los partidos aprobaron la designación de los magistrados. Ello es importante, porque por esa vía los institutos locales (e incluso los tribunales locales) actúan bajo la premisa que sus acuerdos y resoluciones pueden ser revisados por el Tribunal Electoral del Poder Judicial de la Federación. Con ello, las elecciones en los estados no solo tienen un piso común — del que ya hablamossino un techo de control. Un control jurisdiccional sobre los institutos.

Nadie -insisto - en su sano juicio puede pretender suprimir los conflictos electorales. Las energías y pasiones que desatan los comicios así como los errores de la autoridad y las estrategias de los partidos, de vez en vez construyen diferendos de muy diverso grado e intensidad. Lo importante, sin embargo, es contar con una vía y una institución capaz de resolverlos, y para ello (por fortuna) contamos con el TEPJF.

\section{¿Tienes alguna propuesta para reforzar la autonomía de los institutos locales diferente a la creación del INE?}

Aumentar el período de la función. En algunos estados el período de los consejeros es apenas de tres años, lo que supone operar en una sola elección. Esa corta estadía los vuelve vulnerables y evita una cierta profesionalización de la función, por ello, establecer desde la Constitución un período de tiempo similar al que ahora cubren los consejeros del IFE no parece una mala recomendación. 
Incrementar el porcentaje de votos que se requiere para su nombramiento. Hoy, los congresos locales, por lo menos en su composición, han dejado de ser aquellas cajas de resonancia inercial de los gobernadores. El pluralismo equilibrado que los habita reclama, en la mayoría de los casos, operaciones de acercamiento entre fuerzas políticas distintas y en ocasiones, enfrentadas. Pues bien, se podría acrecentar el porcentaje de votos necesarios para ser nombrado consejero electoral local de tal suerte que ningún partido político — en singular - pudiera nombrarlos.

Igualmente se podría reforzar la independencia de su presupuesto para que no se vieran sujetos a los vaivenes de la política local. Porque ya se sabe que la "llave del dinero" puede ser un instrumento de presión sobre órganos que constitucionalmente deben ser autónomos.

\section{¿Entonces se trataría de apuntalar diversos aspectos tanto del IFE como de los institutos locales?}

Es conveniente volver a lo básico: $a$ ) descargar al IFE y a los institutos locales de sus funciones como juez y reforzar a las instituciones administrativas encargadas de organizar las elecciones ciñéndolas a su papel, $b$ ) al mismo tiempo, reforzar la vía jurisdiccional para resolver controversias, subrayando la definitividad de las etapas y actos del proceso electoral y estableciendo con claridad que el Tribunal Electoral del Poder Judicial de la Federación debe en todo caso - salvo asuntos específicos- resolver en definitiva los asuntos que lleguen a su mesa, tratando de acabar con el "pin pon" perverso que desgasta al IFE y al Tribunal, y c) estableciendo que las condiciones equilibradas de la competencia son y deben ser un piso - modelado con el financiamiento público y el acceso de los partidos a la radio y la televisión-, en que los funcionarios públicos no deben distraer recursos para apoyar a los partidos, que debe existir un tope de gastos de campaña, pero que el resto debe verse como "el reino de la libertad".

A diferencia del Pacto, los senadores del PAN y el PRD solamente desean darle facultades al Senado para que eventualmente pueda desaparecer al órgano electoral local y encargarle la organización de las elecciones respectivas al IFE. No postulan la creación de un Instituto Nacional que se encargué de todas las elecciones, es decir, solo en casos excepcionales el Instituto Federal Electoral intervendría en la organización de los comicios locales, es una receta menos drástica. 
Una especie de espada de Damocles que flotará sobre las cabezas de los institutos locales si empiezan a volverse facciosos, a perder independencia, a no ofrecer garantías de imparcialidad a los contendientes, algo que se emparenta con lo que ya establece el artículo 41 de la Constitución cuando señala que el IFE asumirá la organización de los comicios locales cuando las autoridades competentes en esa entidad así lo soliciten. 